\title{
Respon Siswa Sekolah Menengah Atas Terhadap Pembelajaran Luar Kelas Berbasis Sains Bus Untuk Meningkatkan Keterampilan Literasi Siswa
}

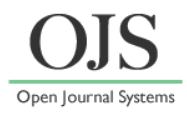

\author{
Reza Stefani Carlesia*, Nadi Suprapto \\ Jurusan Fisika, Fakultas Matematika dan Ilmu Pengetahuan Alam, Universitas Negeri Surabaya \\ *Email: reza.17030184072@ mhs.unesa.ac.id \\ DOI: https://doi.org/10.33369/pendipa.6.1.8-15
}

\begin{abstract}
[High School Student Responses to Science-based Outdoor Learning to Improve Student Literacy Skills]. This study was conducted to analyze the response of high school students to learning outside the classroom based on Science bus to improve students' literacy skills. The method in the research using quantitative descriptive, implemented in March-April 2021 at the time of the covid-19 pandemic. The population is students of public and private senior high schools throughout Surabaya distributed from grades X, XI, XII. Cluster random sampling was used as sampling technique in this study. The samples were 100 students from class X, XI, XII SMAN 4 Surabaya, SMAN 7 Surabaya, SMAN 9 Surabaya, SMAN 15 Surabaya, SMAN 17 Surabaya, SMA Wachid Hasyim 5, and SMAK Karitas III. Based on the results of the study conducted through test data and questionnaires, it was concluded that the science literacy skills of high schools in Surabaya specifically in the material of Regular Straight Motion (GLB) and Regular Straight Motion Change (GLBB) are in the low category. One solution that the author can offer about this is to implement learning outside the classroom by utilizing the local wisdom of Surabaya, namely surabaya buses. It is also supported by the results of the poll, where $92 \%$ of students need new activities in learning, $85 \%$ are interested if learning on GLB and GLBB materials is done on the Surabaya bus, and $86 \%$ agree that learning on the bus can improve students' literacy skills, especially in GLB and GLBB materials.
\end{abstract}

Keywords: Outdoor Learning, Straight Motion Kinematics, Literacy Skills.

\begin{abstract}
ABSTRAK
Penelitian ini dilakukan untuk menganalisis respon siswa sekolah menengah atas terhadap pembelajaran luar kelas berbasis Sains bus untuk meningkatkan keterampilan literasi siswa. Metode pada penelitian menggunakan deskriptif kuantitatif, dilaksanakan pada bulan Maret-April 2021 pada saat pandemi covid19. Adapun Populasinya merupakan siswa Sekolah Menengah Atas (SMA) negeri dan swasta di seluruh Surabaya yang terdistribusi dari kelas X, XI, XII. Cluster random sampling digunakan sebagai Teknik pengambilan sampel pada penelitian ini. Adapun sampelnya adalah 100 siswa dari kelas X, XI, XII SMAN 4 Surabaya, SMAN 7 Surabaya, SMAN 9 Surabaya, SMAN 15 Surabaya, SMAN 17 Surabaya, SMA Wachid Hasyim 5, dan SMAK Karitas III. Berdasarkan hasil penelitian yang penulis lakukan melalui data tes dan angket, didapatkan kesimpulan bahwa keterampilan literasi sains SMA di Surabaya khususnnya pada materi Gerak Lurus Beraturan (GLB) dan Gerak Lurus Berubah Beraturan (GLBB) berada pada kategori rendah. Salah satu solusi yang dapat penulis tawarkan mengenai hal tersebut adalah menerapkan pembelajaran luar kelas dengan memanfaatkan kearifan lokal kota Surabaya yakni bus Surabaya. Hal tersebut juga didukung dengan hasil angket, dimana sebesar $92 \%$ siswa membutuhkan kegiatan baru dalam pembelajaran, sebesar $85 \%$ tertarik jika pembelajaran pada materi GLB dan GLBB di lakukan di dalam bus Surabaya, dan sebesar $86 \%$ setuju bahwa pembelajaran di dalam bus dapat meningkatkan keterampilan literasi siswa khususnya pada materi GLB dan GLBB.
\end{abstract}

Kata kunci: Pembelajaran Luar Kelas, Kinematika Gerak Lurus, Keterampilan Literasi. 


\section{PENDAHULUAN}

Pendidikan didefinisikan sebagai suatu usaha siswa dalam keadaan sadar dan terencana agar dapat mewujudkan proses pembelajaran dengan suasana yang aktif sebagai upaya untuk mengembagkan potensi pada diri siswa agar memiliki kecerdasan, akhlak mulia, kekuatan spiritual keagamaan, pengendalian diri, dan keterampilan lain yang diperlukan dalam diri masyarakat dan siswa itu sendiri (UU RI No. 20 Tahun 2003). Dalam pendidikan dikenal istilah kurikulum. Indonesia sampai saat ini telah mengalami 11 kali pergantian kurikulum. Kurikulum yang saat ini telah digunakan yaitu kurikulum 2013 revisi 2017. Gerakan literasi merupakan salah satu dari 4 pilar yang ditekankan pada kurikulum 2013 revisi 2017.

Keterampilan literasi sains merupakan keterampilan individu menggunakan pengetahuannya dalam memecahkan masalah yang didapat pada kehidupan di sekitarnya. Indonesia termasuk dalam kategori dengan keterampilan literasi sains siswa yang rendah. Indonesia juga mengalami penurunan skor berdasarkan hasil penilaian Programme for International Student Assessment (PISA). pada tahun 2015 hasil rata-rata skor bidang literasi sains negara-negara OECD sebesar 493, siswa Indonesia hanya mencapai skor 403 (OECD, 2015b). sedangkan hasil penilaian PISA tahun 2018 menunjukkan bahwa siswa Indonesia mengalami penurunan skor menjadi 396 dari rata-rata skor yang diperoleh negara-negara OECD sebesar 489 (OECD, 2018).

Menurut PISA, dalam OECD (2015a) literasi sains didasari oleh pengukuran keterampilan dari 4 domain, yaitu: 1) Domain konteks, yakni dalam konteks tertentu (pribadi, lokal/nasional, dan global) siswa dinilai berdasarkan pengetahuan dan kompetensinya; 2) Domain kompetensi, berorientasi pada keterampilan siswa dalam menjelaskan peristiwa secara ilmiah, mengevaluasi dan merancang penelitian ilmiah, serta menginterpretasi data dan bukti secara ilmiah; 3) Domain pengetahuan, berorientasi pada pengetahuan siswa terhadap konten, prosedural, dan epistemik; 4) Domain sikap, sikap minat pada sains yang ditunjukkan oleh siswa untuk mendukung penelitian ilmiah, dan motivasi siswa dalam bertindak secara bertanggungjawab terhadap lingkungan sekitar.
Gagne mengatakan bahwa dibutuhkan siswa yang berada pada posisi proses mental yang aktif dalam pembelajaran, selain itu pendidik juga memiliki fungsi untuk mengkondisikan terjadinya proses pembelajaran (Gagne, 1996). Berdasarkan uraian diatas didapatkan kesimpulan bahwa pembelajaran adalah sistem yang diajarkan kepada siswa agar memenuhi capaian yang diharapkan sesuai dengan pedoman yang ada, dan pada lingkungan yang telah ditentukan dengan kondisi mental siswa yang aktif sehingga dapat mengalami perubahan secara utuh dan menyeluruh. Kondisi siswa yang aktif disini dapat diinterpretasikan dalam keadaan dimana siswa siap menerima pembelajaran yang diberikan oleh pendidik, tidak dalam keadaan mengantuk atau jenuh. Siswa diharapkan ada pada kondisi senang dan dapat memupuk motivasi belajar yang tinggi untuk bisa menyerap seluruh pembelajaran yang diberikan oleh pendidik secara utuh dan menyeluruh.

Untuk menciptakan suasana ini, maka diperlukan kegiatan pembelajaran dengan konsep yang baru. Salah satunya yaitu kegiatan pembelajaran berbasis luar kelas (outdoor learning). Dengan adanya pembelajaran di luar kelas maka diharapkan siswa akan lebih termotivasi dalam menciptakan sendiri pengetahuannya yang didapatkan dari pengalamannya dengan lingkungan. Seperti kata pepatah yang mengatakan "Pengalaman Adalah Guru Terbaik". Pembelajaran luar kelas dapat dilakukan dengan berbagai media, salah satunya yaitu bus. Sains bus merupakan media pembelajaran sains yang dilakukan di dalam bus. Menurut Kamus Besar Bahasa Indonesia (KBBI) bus adalah kendaraan bermotor dengan angkutan umum yang besar, beroda empat atau lebih yang dapat memuat orang banyak. Kegiatan yang dilakukan pada pembelajaran luar kelas berbasis Sains bus yaitu siswa menggunakan seluruh panca indera untuk mengamati dan merasakan seluruh kegiatan selama di dalam bus serta dapat menginterpretasikannya pada materi yang akan dipelajari.

Taqwa dan Haji (2019) dalam penelitiannya memperoleh hasil adanya pengaruh keterampilan pemecahan masalah pada siswa yang dilakukan dengan outdoor learning sebesar 97,9\%. Dari hasil analisis skor dapat diketahui bahwa kelas eksperimen yaitu dengan outdoor learning 
mendapatkan skor rata - rata 78,79 sedangkan kelas kontrol dengan indoor learning mendapatkan skor rata-rata 73,86. Selain itu, berdasarkan penelitian Ismail dan Suprapto (2021) dapat diketahui bahwa pengunjung atau masyarakat setuju apabila aktivitas field trips dikaitkan dengan kurikulum sekolah. Outdoor learning dapat dilakukan melalui field trips seperti berkunjung di Jatim Park bagi masyarakat Malang. Selain itu outdoor learning juga dapat dilakukan dengan menggunakan kearifan lokal yang ada pada tiap daerah. Kearifan lokal pada setiap daerah tentu berbedabeda. Salah satu kearifan lokal yang ada di Surabaya yaitu bus Surabaya, dimana transportasi bus Surabaya ini dapat diakses hanya dengan menukarkan botol plastik bekas. Kearifan lokal yang ditemukan ini dapat diintegrasikan ke dalam materi fisika dengan pokok bahasan kinematika gerak lurus khususnya pada materi Gerak Lurus Beraturan (GLB) dan Gerak Lurus Berubah Beraturan (GLBB). Hasil penelitian Adani et al., (2018) menyimpulkan bahwa literasi sains siswa pada materi gerak lurus dikategorikan rendah. Dengan demikian pemanfaatan transportasi bus Surabaya diharapkan dapat memotivasi keinginan belajar siswa, serta dapat mempengaruhi hasil belajar pesrta didik menjadi lebih baik terutama dalam keterampilan literasi sains yang dimiliki oleh siswa.

Berdasarkan uraian di atas, dengan memadukan salah satu tujuan pembelajaran berdasarkan kurikulim 2013 revisi 2017 yaitu gerakan literasi dengan pembelajaran outdoor learning yang memanfaatkan kearifan lokal yang ada di kota Surabaya, maka peneliti tertarik untuk menganalisis "Respon Siswa Sekolah Menengah Atas Terhadap Pembelajaran Luar Kelas Berbasis Sains bus Untuk Meningkatkan Keterampilan Literasi Siswa."

\section{METODE PENELITIAN}

Metode yang digunakan adalah penelitian deskriptif kuantitatif yang menggambarkan suatu keadaan nyata tanpa memberikan suatu perlakuan terhadap subjek penelitian (Sukmadinata, 2012).

Penelitian ini dilaksanakan pada bulan Maret-April 2021 pada masa pandemi covid-19. Adapun populasi dalam penelitian ini adalah siswa Sekolah Menengah Atas (SMA) negeri dan swata di seluruh Surabaya yang terdistribusi dari kelas X, XI, XII, dengan Teknik pengambilan sampel Cluster random sampling. Sampel penelitian ini adalah 100 siswa dari kelas X, XI, XII SMAN 4 Surabaya, SMAN 7 Surabaya, SMAN 9 Surabaya, SMAN 15 Surabaya, SMAN 17 Surabaya, SMA Wachid Hasyim 5, dan SMAK Karitas III.

Teknik pengambilan data pada penelitian ini digunakan angket dan tes berbentuk soal esai dengan jumlah 3 butir soal dalam bentuk google form yang disebarkan pada siswa SMA di Surabaya. Adapun tujuan tes digunakan untuk mengukur profil literasi sains pada siswa dan angket digunakan untuk menganalisis respon siswa terkait pembelajaran outdoor learning berbasis sains bus untuk meningkatkan keterampilan literasi sains pada siswa. Pengukuran keterampilan literasi sains dapat dilakukan dengan menganalisis penguasaan siswa dalam setiap domain literasi sains (Ani Rusilowati et al., 2016). Pada peneitian ini, domain keterampilan literasi sains yang diukur yaitu domain kompetensi. Proses sains yang terlibat ketika menjawab suatu pertanyaan atau memecahkan masalah dapat dirujuk pada kompetesensi dalam literasi sains, khususnya pada indikator menginterpretasikan data dan menunjukkan fakta secara ilmiah. Pada indikator ini siswa diharap mampu untuk mengubah data dari satu representasi atau gambaran ke representasi lainnya; menganalisis dan menafsirkan data serta menarik kesimpulan dengan tepat (OECD, 2015a).

Analisis data tes dilakukan menggunakan persentase ketercapaian domain kompetensi pada keterampilan literasi sains fisika Adapun interpretasi data dari persentase ditunjukkan oleh Tabel 1. Analisis data pada angket dilakukan secara deskriptif berdasarkan hasil pilihan siswa.

Tabel 1. Kategori Interpretasi Data Skor (Purwanto, 2013)

\begin{tabular}{cc}
\hline Kategori & Interval \\
\hline Sangat Tinggi & $86-100$ \\
Tinggi & $76-85$ \\
Sedang & $60-75$ \\
Rendah & $55-59$ \\
Sangat Rendah & $<54$ \\
\hline
\end{tabular}




\section{HASIL DAN PEMBAHASAN}

Hasil analisis data didapatkan bahwa pada materi kinematika gerak lurus khususnya pada materi Gerak Lurus Beraturan (GLB) dan Gerak Lurus Berubah Beraturan (GLBB), profil keterampilan literasi sains siswa Sekolah Menengah Atas (SMA) di Surabaya masih berada pada kategori sangat rendah dan dapat dilihat pada Tabel 2 dengan rincian persentase skor per indikator dapat dilihat pada Tabel 3 .

Tabel 2. Profil keterampilan literasi siswa di Surabaya secara umum

\begin{tabular}{ccc}
\hline Kategori & Frekuensi & Persentase \\
\hline Sangat Tinggi & 5 & $5 \%$ \\
Tinggi & 2 & $2 \%$ \\
Sedang & 2 & $2 \%$ \\
Rendah & 1 & $1 \%$ \\
Sangat Rendah & 90 & $90 \%$ \\
\hline Jumlah & 100 & $100 \%$ \\
\hline
\end{tabular}

Tabel 3. Persentase skor per indikator keterampilan literasi sains siswa SMA di Surabaya

\begin{tabular}{|c|c|c|c|}
\hline No. & Indikator & Persentase & Kategori \\
\hline 1 & $\begin{array}{l}\text { Memecahkan } \\
\text { masalah kon- } \\
\text { tekstual pada } \\
\text { materi GLB }\end{array}$ & $75.6 \%$ & Sedang \\
\hline 2 & $\begin{array}{l}\text { Memecahkan } \\
\text { masalah kon- } \\
\text { tekstual pada } \\
\text { kombinasi ma- } \\
\text { teri GLB dan } \\
\text { GLBB dengan } \\
\text { diberikan } \\
\text { grafik }\end{array}$ & $27,4 \%$ & $\begin{array}{l}\text { Sangat } \\
\text { Rendah }\end{array}$ \\
\hline 3 & $\begin{array}{l}\text { Memecahkan } \\
\text { masalah kon- } \\
\text { tekstual pada } \\
\text { kombinasi ma- } \\
\text { teri GLB dan } \\
\text { GLBB dengan } \\
\text { diberikan ilus- } \\
\text { trasi gambar } \\
\text { nyata }\end{array}$ & $23 \%$ & $\begin{array}{l}\text { Sangat } \\
\text { Rendah }\end{array}$ \\
\hline
\end{tabular}

Hasil pada Tabel 2 menunjukkan dari seluruh siswa kelas X, XI, XII SMA di Surabaya dapat disimpulkan bahwa siswa dengan keterampilan literasi sains sangat tinggi sebanyak 5\% dari 100 siswa, siswa dengan keterampilan literasi sains tinggi sebanyak $2 \%$ dari 100 , siswa dengan keterampilan literasi sains sedang sebanyak $2 \%$ dari 100, siswa dengan keterampilan literasi sains rendah sebanyak $1 \%$ dari 100, dan siswa dengan keterampilan literasi sains sangat rendah sebanyak $90 \%$ dari 100 siswa. Hal ini sejalan dengan penelitian (Mukharomah et al., 2021) yang mendapatkan hasil sebesar $52,51 \%$, dimana indikator domain kompetensi menginterpretasikan data dan bukti ilmiah masih pada kategori rendah. Selain itu pada penelitian (Merta et al., 2020) didapatkan hasil yang sama dimana, indikator domain kompetensi yang paling rendah terdapat pada menginterpretasikan data dan bukti secara ilmiah. Hal ini dapat terjadi karena hafalan teori, hukum, dan konsep yang hanya beroreintasi pada nilai masih bertumpu pada proses pembelajaran (Arisman, 2015).

\section{Soal nomor 1}

Andi, Roni, Sita, Dewi, dan Mahmud bersekolah di SMAN 7 Surabaya. Mereka berangkat dengan kecepatan yang sama yaitu $40 \mathrm{~km} /$ jam. Jarak Andi ke sekolah 8 km, jarak Roni ke sekolah 10 km, jarak Sita ke sekolah $16 \mathrm{~km}$, jarak Dewi ke sekolah 20 $\mathrm{km}$, dan jarak Mahmud ke sekolah $24 \mathrm{~km}$. Tentukan waktu yang tepat dari masingmasing siswa harus berangkat dari rumah ke sekolah jika bel masuk SMAN 7 berbunyi pukul 06.30, siswa wajib hadir 5 menit sebelum bel berbunyi dan traffic light diabaikan!

Indikator soal nomor 1 adalah memecahkan masalah kontekstual pada materi GLB. Sooal tersebut berisi pnentukan waktu yang tepat pada kelima siswa dengan jarak rumah ke sekolah yang berbeda-beda tetapi memiliki kecepatan yang sama. Siswa diharapkan dapat menentukan waktu yang tepat pada masing-masing siswa pada soal agar tidak terlambat datang ke sekolah. Pada Tabel 3 persentase jawaban siswa pada soal ini mencapai $75,6 \%$. Hal tersebut berorientasi bahwa sebagian siswa belum mampu menjawab dan memecahkan masalah pada soal dengan tepat. Berdasarkan tingkatan kategorinya, persentase jawaban siswa pada soal ini 
menduduki kategori sedang. Memecahkan masalah kontekstual yaitu masalah-masalah yang dikaitkan dengan fenomena atau kejadian dalam kehidupan sehari-hari masih menjadi kesulitan siswa.

\section{Soal nomor 2}

Weni bersekolah di SMAN 4 Surabaya. Setiap hari Weni pulang sekolah naik bus Surabaya. Jarak halte SMAN 4 Surabaya ke halte Panglima Sudirman yaitu $2 \mathrm{~km}$. Bus tiba di halte SMAN 4 Surabaya pada pukul 12.38. Setelah berhenti selama 3 menit, bus kembali melaju. Setelah $100 \mathrm{~m}$ bus melaju dengan kecepatan konstan sebesar 36 $\mathrm{km} / \mathrm{jam}$. Pada jarak $1 \mathrm{~km}$ dari halte SMAN 4 Surabaya terdapat traffic light dengan waktu tunggu traffic light dari warna merah hingga hijau 120 detik dan bus melakukan pengereman pada jarak $100 \mathrm{~m}$ sebelum traffic light. Setelah $100 \mathrm{~m}$ dari bus berhenti pada traffic light, bus kembali melaju dengan kecepatan konstan 36 km/jam. Pada pukul berapa Weni sampai di halte Panglima Sudirman jika bus melakukan pengereman pada jarak $100 \mathrm{~m}$ sebelum bus tiba di halte Panglima Sudirman?

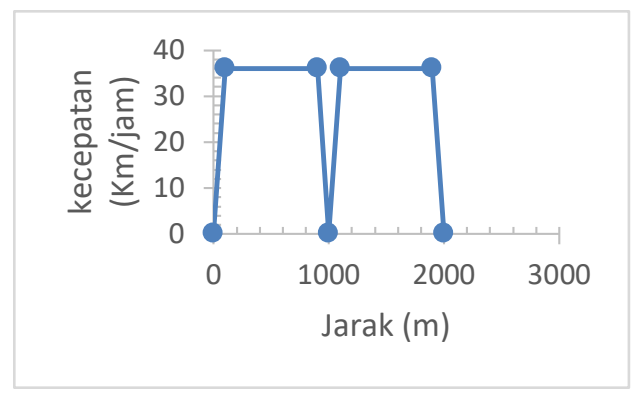

Gambar 1. Grafik penjelasan soal nomor 2. Sumber: Dokumen pribadi

Indikator soal nomor 2 adalah memecahkan masalah kontekstual pada kombinasi materi GLB dan GLBB dengan diberikan tambahan grafik. Soal tersebut berisi penentukan waktu yang tepat seorang siswa sampai di sebuah halte, dimana pada perjalanan sebuah bus tersebut mengalami kombinasi gerak GLB dan GLBB. Pada Tabel 3 persentase jawaban siswa pada soal ini mencapai $27,4 \%$. Hal tersebut menunjukkan bahwa Sebagian besar siswa belum mampu menjawab dan memecahkan masalah pada soal dengan tepat. Berdasarkan tingkatan kategorinya, persentase jawaban siswa pada soal ini menduduki kategori sangat rendah. Siswa masih sangat kesulitan dalam memecahkan masalah kontekstual yaitu masalah-masalah yang dikaitkan dengan fenomena atau kejadian dalam kehidupan sehari-hari.

\section{Soal nomor 3.}

Dini akan berangkat ke sekolah menggunakan bus Surabaya. Dini berangkat dari halte IP Surabaya menuju halte Darmo SM. Jarak kedua halte tersebut $100 \mathrm{~m}$. Bus tiba di halte IP pukul 06.00. Setelah berhenti selama 3 menit, bus kembali melaju. Setelah $20 \mathrm{~m}$, bus melaju dengan kecepatan konstan sebesar $18 \mathrm{~km} / \mathrm{jam}$. Pada jarak $50 \mathrm{~m}$ dari halte IP terdapat traffic light dengan waktu tunggu traffic light dari warna merah hingga hijau 84 detik dan bus melakukan pengereman pada jarak $20 \mathrm{~m}$ sebelum traffic light. Setelah $20 \mathrm{~m}$ dari bus berhenti pada traffic light, bus kembali melaju dengan kecepatan konstan $18 \mathrm{~km} / \mathrm{jam}$. Pada pukul berapa Dini sampai di halte Darmo SM jika bus melakukan pengereman pada jarak $20 \mathrm{~m}$ sebelum bus tiba di halte Darmo SM?

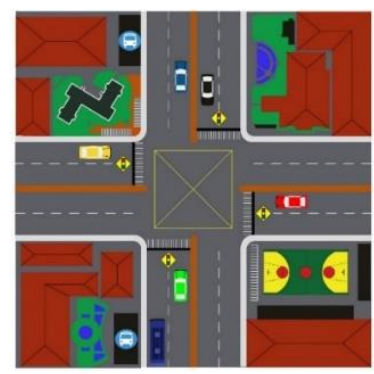

Gambar 2. Ilustrasi gambar pada keadaan nyata penjelasan soal nomor 3. Sumber: Dokumen pribadi

Indikator soal nomor 3 sama dengan indikator soal nomor 2, hanya saja informasi pendukung yang semula direpresentasikan dengan grafik diubah menjadi representasi dalam bentuk ilustrasi gambar pada keadaan nyata dalam kehidupan sehari-hari. Pada Tabel 3 diketahui bahwa persentase jawaban siswa pada soal ini mencapai $23 \%$. Hal tersebut menujukkan bahwa sebagian besar siswa belum mampu menjawab dan memecahkan masalah pada soal dengan tepat. Berdasarkan tingkatan kategorinya, 
persentase jawaban siswa pada soal ini menduduki kategori sangat rendah, memecahkan masalah kontekstual yaitu masalah-masalah yang dikaitkan dengan fenomena atau kejadian dalam kehidupan sehari-hari masih menjadi kesulitan siswa.

Analisis jawaban siswa nomor 2 dan 3, dimana siswa belum mampu menafsirkan fenomena dalam bentuk konstekstual yang disertai grafik dan gambar ilustrasi nyata mendukung penelitian (Ning et al., 2020) dimana memprediksi peristiwa yang berkaitan dengan kehidupan sehari-hari secara ilmiah serta dampak dari perubahan tersebut masih menjadi kesulitan bagi Sebagian besar siswa.

\section{Respon siswa}

Hasil angket respon siswa SMA di Surabaya terhadap pembelajaran luar kelas berbasis sains bus untuk meningkatkan keterampilan literasi siswa dapat dilihat pada Tabel 4.

Tabel 4. Respon siswa SMA di Surabaya terhadap pembelajaran luar kelas berbasis Sains bus untuk meningkatkan keterampilan literasi siswa

\begin{tabular}{|c|c|c|c|}
\hline No. & Pernyataan & SS & $\mathbf{S}$ \\
\hline 1. & $\begin{array}{l}\text { Pembelajaran fisika se- } \\
\text { belum pandemi sepenuh- } \\
\text { nya dilakukan di dalam } \\
\text { kelas maupun laboratori- } \\
\text { um. }\end{array}$ & $27 \%$ & $65 \%$ \\
\hline 2. & $\begin{array}{l}\text { Pembelajaran fisika sudah } \\
\text { pernah dilakukan di luar } \\
\text { kelas. }\end{array}$ & $6 \%$ & $53 \%$ \\
\hline 3. & $\begin{array}{l}\text { Mata pelajaran fisika pada } \\
\text { materi kinematika gerak } \\
\text { lurus khususnya materi } \\
\text { Gerak Lurus Beraturan } \\
\text { (GLB) dan Gerak Lurus } \\
\text { Berubah Beraturan } \\
\text { (GLBB) merupakan } \\
\text { materi yang mudah } \\
\text { dipelajari. }\end{array}$ & $8 \%$ & $73 \%$ \\
\hline 4. & $\begin{array}{llr}\text { Saya menyukai materi } \\
\text { kinematika gerak lurus } \\
\text { khususnya materi } \\
\text { dan GLBB. }\end{array}$ & $8 \%$ & $64 \%$ \\
\hline 5. & $\begin{array}{l}\text { Guru mengaitkan materi } \\
\text { kinematika gerak lurus }\end{array}$ & $17 \%$ & $79 \%$ \\
\hline
\end{tabular}

khususnya materi GLB

dan GLBB dengan

kehidupan sehari-hari.

Kegiatan pembelajaran di dalam kelas maupun di laboratorium pada materi

6. kinematika gerak lurus $\mathbf{7 \%} \quad \mathbf{7 8 \%}$ khususnya materi GLB dan GLBB menyenangkan.

Saya membutuhkan kegiatan baru dalam pembelajaran misalnya pembe-

7. lajaran di luar kelas pada materi kinematika gerak lurus khususnya materi GLB dan GLBB.

Saya tertarik jika pembelajaran pada materi

8. kinematika gerak lurus $\mathbf{2 3 \%} \quad \mathbf{6 2 \%}$ khususnya materi GLB dan GLBB dilakukan di dalam bus Surabaya.

Durasi waktu yang berbeda pada traffic light mempengaruhi jenis

9. gerak saya pada peristiwa $\quad \mathbf{1 7 \%} \quad \mathbf{7 5 \%}$ GLB dan GLBB saat saya berangkat dan pulang dari sekolah.

Jumlah traffic light mempengaruhi jenis

10. gerak saya pada peristiwa $\quad \mathbf{1 7 \%} \quad \mathbf{7 2 \%}$ GLB dan GLBB saat saya berangkat dan pulang sekolah.

Kecepatan Bus Surabaya mempengaruhi jenis

$\begin{array}{lll}\text { 11. gerak bus pada peristiwa } & \mathbf{1 9 \%} & \mathbf{7 5 \%}\end{array}$ GLB dan GLBB.

Saya pernah menceritakan konsep fisika yang berkaitan dengan kehidupan sehari-hari khusus-

12. nya pada materi GLB dan $1 \% \quad 61 \%$ GLBB kepada orang lain (teman, keluarga, saudara).

13. Saya mengetahui bahwa $\mathbf{1 1 \%}$ 


\begin{tabular}{lll}
\hline terdapat materi fisika & $\mathbf{8 2 \%}$ \\
kinematika gerak lurus & & \\
khususnya pada materi & & \\
GLB dan GLBB pada saat & & \\
saya naik bus. & & \\
Pembelajaran di dalam & & \\
bus dapat meningkatkan & & $\mathbf{7 0 \%}$ \\
keterampilan literasi & $\mathbf{1 6 \%}$ & $\mathbf{7 0}$ \\
siswa khususnya pada & & \\
materi GLB dan GLBB. & & \\
\hline
\end{tabular}

Pada tabel 4 diketahui bahwa 92\% siswa menyatakan pembelajaran fisika sebelum pandemi dilakukan di dalam kelas maupun laboratorium sepenuhnya. Sebesar 59\% siswa menyatakan pembelajaran fisika sudah pernah dilakukan di luar kelas. Sebesar $81 \%$ siswa mudah mempelajari materi kinematika gerak lurus khusunya pada materi GLB dan GLBB. Sebesar $72 \%$ siswa menyukai materi GLB dan GLBB. Sebesar 96\% guru mengaitkan materi pada kehidupan sehari-hari. Sebesar $85 \%$ siswa merasa senang mengikuti kegiatan pembelajaran di dalam kelas maupun di laboratorium. Sebesar 92\% siswa membutuhkan kegiatan baru dalam pembelajaran. Sebesar $85 \%$ tertarik jika pembelajaran pada materi GLB dan GLBB di lakukan di dalam bus Surabaya. Sebesar 92\% mengetahui bahwa durasi waktu yang berbeda pada traffic light mempengaruhi jenis gerak. Sebesar $89 \%$ siswa mengetahui bahwa jumlah traffic light mempengaruhi jenis gerak. Sebesar $62 \%$ siswa pernah menceritakan konsep fisika yang berkaitan dengan kehidupan sehari-hari kepada orang lain. Sebesar 93\% mengetahui bahwa terdapat materi fisika khususnya GLB dan GLBB pada saat naik bus. Sebesar $86 \%$ setuju bahwa pembelajaran di dalam bus dapat meningkatkan keterampilan literasi siswa khususnya pada materi GLB dan GLBB. Hal ini sesuai dengan hasil penelitian Sulsilah et al (2019) dimana pendekatan saintifik dapat digunakan untuk meningkatkan keterampilan literasi sains siswa. Maka dari itu diperlukan pendekatan saintifik agar siswa dapat menikmati pengetahuan, meningkatkan kreatifitas, menemukan keterkaitan, dan bertanggung jawab dalam memecahkan masalah yang ada di sekitar siswa (Asyhari, 2015). Pembelajaran luar kelas berbasis sains bus merupakan salah satu cara menerapkan proses pembelajaran dengan pendekatan saintifik.

\section{KESIMPULAN}

Berdasarkan hasil penelitian yang penulis lakukan melalui data tes dan angket, didapatkan kesimpulan bahwa keterampilan literasi sains siswa Sekolah Menengah Atas (SMA) di Surabaya khususnnya pada materi Gerak Lurus Beraturan (GLB) dan Gerak Lurus Berubah Beraturan (GLBB) berada pada kategori rendah. Salah satu solusi yang dapat penulis tawarkan mengenai hal tersebut adalah menerapkan pembelajaran luar kelas dengan memanfaatkan kearifan lokal kota Surabaya yakni bus Surabaya. Hal tersebut juga didukung dengan hasil angket, dimana sebesar $92 \%$ siswa membutuhkan kegiatan baru dalam pembelajaran, sebesar $85 \%$ tertarik jika pembelajaran pada materi Gerak Lurus Beraturan (GLB) dan Gerak Lurus Berubah Beraturan (GLBB) dilakukan di dalam bus Surabaya, dan sebesar $86 \%$ setuju bahwa pembelajaran di dalam bus dapat meningkatkan keterampilan literasi siswa khususnya pada materi GLB dan GLBB.

\section{UCAPAN TERIMA KASIH}

Ucapkan terima kasih disampaikan penulis kepada Ibu Dra. Suliyanah, M.Si. dan Bapak Utama Alan Deta, M.Pd., M.Si. sebagai validator, guru fisika di SMA Negeri 7 Surabaya, Bapak Yuhanes Hari Nugroho, S.Pd. serta wakil kepala sekolah SMA Negeri 7 Surabaya, Bapak Drs. Siswo Yunarso, M.Si., yang sudah berkenan membantu penulis selama melakukan kegiatan penelitian.

\section{DAFTAR PUSTAKA}

Arisman, A. (2015). Penerapan Pembelajaran Kooperatif Tipe Stad Dengan Metode Praktikum Dalam Pembelajaran IPA Terpadu Untuk Meningkatkan Literasi Sains Siswa. Prosiding Seminar Nasional Fisika (EJournal) SNF2015 IV, 89-92.

Asyhari, A. (2015). Profil Peningkatan Keterampilan Literasi Sains Siswa Melalui Pembelajaran Saintifik. Jurnal Ilmiah Pendidikan Fisika Al-Biruni, 4(2), 179. https://doi.org/10.24042/jpifalbiruni.v4i2. 91. 
Gagne, Robert M. (1996). The Condition of Instructions. Second edition. New York: Holt, Richard, and Winston.

Ismail, A., \& Suprapto, N. (2021). Exploration of Physics Concepts in Tourism Sites for Basic Competency of Grade 12. IPF: Inovasi Pendidikan Fisika, Vol 10 No. 1, 302-4496.

Ning, D. R., Roshayanti, F., \& Siswanto, J. (2020). Profil Literasi Sains Dan Berfikir Kreatif Siswa SMP Negeri 11 Pekalongan. Jurnal Edukasi Matematika dan Sains, 8(2), 150. https://doi.org/10.25273/jems.v8i2.6905

Merta, I. W., Artayasa, I. P., Kusmiyati, K., Lestari, N., \& Setiadi, D. (2020). Profil Literasi Sains dan Model Pembelajaran dapat Meningkatkan Keterampilan Literasi Sains. Jurnal Pijar MIPA, 15(3), 223. https://doi.org/10.29303/jpm.v15i3.1889.

Mukharomah, F., Wiyanto, \& Putra N. M. D., (2021). Analisis Keterampilan Literasi Sains Fisika SMA Pada Materi Kinematika Gerak Lurus di Masa Pandemi Covid-19. JoTaLP: Journal of Teaching and Learning Physics, 6(1), 2528-5505.

OECD. (2015a). PISA 2015 Framework. Oecd, March 2015, 52. Diambil dari https://doi.org/10.1177/002214651249014.

OECD. (2015b). PISA Result in Focus.

OECD. (2018). Programme for International Student Assessment (PISA) Result from PISA 2018, 1-10. Diambil dari https://www.oecd.org/pisa/Data.

Purwanto, N. 2013. Pengajaran, Prinsip-prinsip dan Teknik Evaluasi. Bandung: PT. Remaja Rosdakarya.

Rusilowati, A., Astuti, B., \& Rahman, N. A. (2019). How to Improve Student's Scientific Literacy. Journal of Physics: Conference Series, vol 1170 No. 1 p. 012028.
Rusilowati, A., Linuwih, S., \& Nugroho, S. A. (2017). The Profile of Science Literacy Attitudes of Junior High School Students in Purbalingga. Proceeding of ICMSE, vol 4 No. 1 pp. 183-189.

Rusilowati, A., Nugroho, S. A., \& Widiyatmoko, A. (2016). Developing an Instrument of Scientific Literacy Assessment on The Cycle Theme. International Journal of Environmental and Science Education, 11(12), 5718-5727.

Sukmadinata. 2012. Metode Penelitian Pendidikan. Bandung: PT. Remaja Rosdakarya.

Sulsilah, H., Utari, S., \& Saepuzaman, D. (2019). The application of scientific approach to improve scientific literacy on domain competency at secondary school on dynamic electricity topic. Journal of Physics: Conference Series, Vol. 1157, No. 3, p. 032056. https://doi.org/10.1088/17426596/1157/3/032056.

Taqwa, B., \& Haji, S. (2019). Pengaruh Pembelajaran Luar Kelas (Outdoor Learning) Terhadap Keterampilan Pemecahan Masalah Siswa Kelas VII SMP Negeri 05 Seluma, Jurnal Pendidikan Matematika Raflesia Vol 04 No. 01. P 25484435.

Depdiknas. 2003. Undang-Undang RI No. 20 tahun 2003 Tentang Sistem Pendidikan Nasional. Jakarta. 